\title{
Kinetic model of rumen biohydrogenation: fractional rates of fatty acid biohydrogenation and passage*
}

\author{
K.J. Harvatine and M.S. Allen ${ }^{1}$ \\ Department of Animal Science, Michigan State University \\ 2265 G Anthony Hall, East Lansing, MI USA 48824
}

\begin{abstract}
A simple model of rumen fatty acid (FA) metabolism is proposed that allows calculation of first order fractional rates of FA biohydrogenation and passage after determination of ruminal pool size and duodenal flux. The model is used to describe the increased duodenal flow of trans-C18:1 FA in diets supplemented with unsaturated rumen-protected FA (UNS, calcium soaps FA). Increasing UNS increased extent of $\mathrm{C} 18: 2$ and $\mathrm{C} 18: 3$ biohydrogenation, and decreased extent of trans-C18: 1 biohydrogenation. The model allows a mechanistic description of rumen biohydrogenation and determination of the extent of $\mathrm{C} 18: 1$ biohydrogenation.
\end{abstract}

KEY WORDS: biohydrogenation, kinetics, fatty acid

\section{INTRODUCTION}

The rumen modifies dietary FA through isomerization and biohydrogenation of unsaturated FA. Nutritionist's ability to formulate diets for absorbed FA profiles depends on an understanding of rumen FA metabolism. Allen (2000) proposed that the extent of biohydrogenation is determined by characteristics of the fat source, retention time in the rumen, and characteristics of the microbial population. Biohydrogenation is determined by the pool size of available FA, rumen retention time, and bacterial hydrogenation capacity, which is a function of the bacterial population and rumen environment. The objective of the current experiment is development of a research model to mechanistically describe the kinetics of rumen FA metabolism.

\footnotetext{
* Supported in part by Milk Specialities Company, Dundee, IL, USA

${ }^{1}$ Corresponding author: e-mail: allenm@msu.edu
} 


\section{MATERIAL AND METHODS}

A simple model was developed to calculate biohydrogenation rate of unsaturated FA in the rumen (Figure 1). The model assumes that unsaturated FA are not oxidized, but are hydrogenated to a more saturated pool, pool sizes are assumed to represent steady state conditions and biohydrogenation follows first-order kinetics. The model

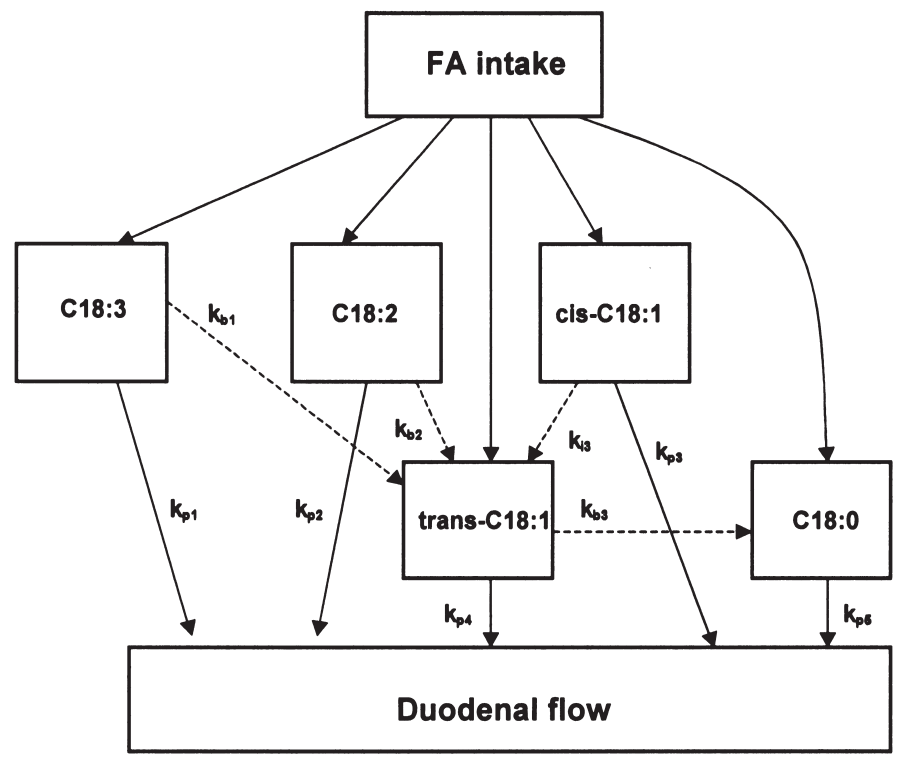

Figure 1. Simplified model of rumen biohydrogenation. The model assumes biohydrogenation of C18:3 $\left(\mathrm{k}_{\mathrm{b} 1}\right)$, and C18:2 $\left(\mathrm{k}_{\mathrm{b} 2}\right)$ to trans-C18:1, and isomerization of cis-C18:1 $\left(\mathrm{k}_{\mathrm{i} 3}\right)$ to trans-C18:1. Finally, trans-C18:1 $\left(\mathrm{k}_{\mathrm{b} 3}\right)$ is biohydrogenated to $\mathrm{C} 18: 0$. The $\mathrm{C} 18: 3$ and $\mathrm{C} 18: 2$ pools represent cis-9,cis-12 C18:2 and cis-9,cis-12,cis-15 C18:3 and do not contain trans isomers. Production of trans-diene intermediates is ignored due to their small pools relative to their large flux. Each FA pool is available for passage and each passes at its own rate signified by different subscripts $\left(\mathrm{k}_{\mathrm{pl}-5}\right)$

was used to calculate the rumen kinetics of rumen-protected unsaturated FA(Ca Soaps of LCFA, Megalac-R ${ }^{\circledR}$, Church and Dwight Company, Inc., Princeton, NJ) in an experiment using eight ruminally and duodenally cannulated Holstein cows arranged in replicated $4 \times 4$ Latin squares with a dose-response arrangement of treatments plus a control. Treatments were diets containing no added protected fat or $2.5 \%$ rumen protected FA from saturated (SAT- prilled hydrogenated free FA, Energy Booster $100^{\circledR}$, Milk Specialties Company Inc.), an intermediate mixture of saturated and unsaturated (INT), or unsaturated FA (UNS- Ca Soaps of LCFA, Megalac-R ${ }^{\circledR}$, Church and Dwight Company, Inc., Princeton, NJ). Experimental diets contained 13.5\% whole cottonseed to provide $2.5 \%$ available FA in the basal diet that also contained $27.5 \% \mathrm{NDF}$ and 
$30.5 \%$ starch. Indigestible NDF was used as a marker to calculate duodenal flow. Ruminal contents were evacuated manually through the ruminal cannula $4.5 \mathrm{~h}$ after feeding and $2 \mathrm{~h}$ before feeding. All samples were lyophilized and FA were extracted according to Sukhija and Palmquist (1988) and measured using gas chromatography.

\section{RESULTS}

Increasing UNS increased intake of cis-C18:1 $(\mathrm{P}<0.001)$ and $\mathrm{C} 18: 2(\mathrm{P}<0.05)$. Duodenal flow of cis and trans-C18:1 was increased by UNS $(\mathrm{P}<0.01)$, but no difference was observed in C18:2 flow with increasing UNS. Ruminal pool size of trans-C18:1 was increased by UNS $(\mathrm{P}<0.001)$, but treatment did not affect ruminal pool size of cis-C18:1 and C18:2. The fractional passage rate for transC18:1 was higher for UNS than CON $(\mathrm{P}<0.05)$ while SAT was not different from $\mathrm{CON}$. The fractional passage rates of $c i s-\mathrm{C} 18: 1$ and $\mathrm{C} 18: 2$ were not affected by treatment. Addition of SAT did not affect rate of biohydrogenation of trans-C18:1 and cis-C18:1 compared to CON. However, UNS linearly decreased rate of biohydrogenation of trans $-\mathrm{C} 18: 1(\mathrm{P}<0.01)$, and tended to increase rate of cis-C18:1 biohydrogenation $(\mathrm{P}<0.08)$. Extent of biohydrogenation of trans-C18:1 was linearly decreased by increasing concentration of unsaturated FA $(\mathrm{P}<0.05)$. There was no difference in extent of biohydrogenation of cis-C18:1, but biohydrogenation of $\mathrm{C} 18: 2$ was increased by increasing unsaturated $\mathrm{FA}(\mathrm{P}<0.05)$.

\section{DISCUSSION}

Biohydrogenation is traditionally reported as the proportion of unsaturated FA or double bonds removed in the rumen (Wu et al., 1991). Although this is an index of rumen metabolism it fails to mechanistically describe FA biohydrogenation. Also, this method is inadequate for calculation of biohydrogenation of monounsaturated FA because appearance from biohydrogenation of more PUFA is not determined. Methods for modeling rumen carbohydrate digestion (Allen and Mertens, 1998) can be applied to rumen FA metabolism. The pool and flux method determines first order rumen passage and digestion rates using duodenal flow and rumen pool size (Firkins et al., 1998). Measuring FA pool size and duodenal passage allows calculation of rumen retention time and determination of the fractional rate of FA biohydrogenation, assuming all disappearance of FA is because of biohydrogenation and not from oxidation or absorption. The model also allows calculation of the extent of biohydrogenation of individual FA calculated from passage and biohydrogenation rates. Conjugated dienes are not modelled because of their small pool size and extremely high rate of biohydrogenation. Individual trans-C18:1 FA also cannot be modelled due to the inability to calculate flux into these pools without labeling methods. 
Fractional rate of biohydrogenation of individual FA in the rumen is an important mechanistic measure because it reports FA biohydrogenation as a proportion of the available FA. The high fractional biohydrogenation rate with UNS indicated poor rumen protection by calcium salts. This is not surprising given that more highly unsaturated FA have a higher pKa (Sukhija and Palmquist, 1990) increasing dissociation of the calcium FA complex within the normal range of ruminal $\mathrm{pH}$. Ruminal $\mathrm{pH}$ in this experiment was moderate and not affected by treatment with a mean of 6.0 .

\section{CONCLUSIONS}

Calculation of individual FA biohydrogenation with a simplified model allows a more mechanistic description of rumen FA biohydrogenation. The ability to predict duodenal FA profile depends on observation and analysis of individual steps of FA metabolism. Modelling biological systems requires assumptions and simplification of unknown or undeterminable events. Assumptions for this model must be tested in the future. It is our hope that this model will be challenged and improved with new experimental data. More complex models may be developed in the future to model production of individual trans isomers, although flux through such pathways require isotope labeling techniques.

\section{REFERENCES}

Allen M.S., Mertens D.R., 1988. Evaluating constraints on fiber digestion by rumen microbes. J. Nutr. 118, 261-270

Allen M.S., 2000. Effects of diet on short-term regulation of feed intake by lactating dairy cattle. J. Dairy Sci. 83, 1598-1624

Beam T.M., Jenkins T.C., Moate P.J., Kohn R.A., Palmquist D.L., 2000. Effects of amount and source of fat on the rates of lipolysis and biohydrogenation of fatty acids in ruminal contents. J. Dairy Sci. 83, 2564-2573

Firkins J.L., Allen M.S., Oldick B.S., St-Pierre N.R., 1998. Modeling ruminal digestibility of carbohydrates and microbial protein flow to the duodenum. J. Dairy Sci. 81, 3350-3369

Sukhija P.S., Palmquist D.L., 1988. Rapid method for determination of total fatty acid content and composition of feedstuffs and feces. J. Agr. Food Chem. 36, 1202-1206

Wu Z., Ohajuruka O.A., Palmquist D.L., 1991. Ruminal synthesis, biohydrogenation, and digestibility of fatty acids by dairy cows. J. Dairy Sci. 74, 3025-3034 